\section{Understanding the Factors Associated with Alcohol Use among Female Sex Workers in a High HIV Prevalence Northeast State of India}

\section{Abstract}

Background: The paper illustrates the factors associated with alcohol use among FSWs in Dimapur, an important commercial hub of Nagaland, which is a high HIV prevalence state of India.

Methods: The analysis is based on 417 FSWs aged 18 years or older who participated in round 2 of Integrated Behavioural and Biological Assessment (IBBA).

Results: There is a significant association between ever consumption of alcohol use in the past month among FSWs and socio-demographic, sexual behaviour and safe sexual practices $(p<0.05)$. Binary logistic regression of Alcohol use among FSWs found that greater than 25 years of FSWs (2.2 times, $P \leq 0.10)$, Divorced/ Separated (0.41 times, $p \leq 0.10)$, >10th standard of education (0.311 times, $p \leq 0.001$ ), drug use ( 5 times, $p \leq 0.001$ ), sharing of injecting drugs with the partner ( 3.7 times, $p \leq 0.001$ ) were independently associated with Alcohol use respectively .Those FSWs have first sex and first started sex work at age 15-20 years were 6.3 ( $p$ $\leq 0.05)$ and $2.4(p \leq 0.05)$ times more likely to use alcohol. One significant finding is those female sex workers were less likely to use alcohol consumption that has 5-9 clients per week. Alcohol using older (25+ years) FSWs were 9 times more likely to have HIV. Married FSWs those using alcohol, were less likely to have HIV, and those alcohol using FSWs aged at first sex was $15-20$ years, 5 times more likely to have HIV seropositivity. Alcohol using FSWs were 30 times more likely to have HIV, who served their client at Lodge/ Hotel.

Conclusion: The findings suggest a need to integrate intervention for alcohol use and related problems in multilevel contexts and with multiple components to effectively reduce alcohol use and to mitigate inconsistent condom use.

Keywords: AIDS; HIV; Female sex workers; Alcohol; India

\section{Santosh Kumar Sharma, Shri Kant Singh and Bedanga Talukdar}

International Institute for Population Sciences, Deonar, Mumbai, Maharashtra, India

Corresponding author:

Santosh Kumar Sharma

\section{戸 santoshiips88@gmail.com skshama96@gmail.com}

International Institute for Population Sciences, Deonar, Mumbai-400 088, Maharashtra, India.

Tel: +2651789400

Citation: Sharma SK, Singh SK, Talukdar B. Understanding the Factors Associated with Alcohol Use among Female Sex Workers in a High HIV Prevalence Northeast State of India. J Infec Dis Treat. 2016, 2:1.

Received: June 25, 2016; Accepted: June 28, 2016; Published: June 30, 2016

\section{Introduction}

Female Sex workers are highly vulnerable to, life threatened disease like HIV, poor physical, mental, social health, anxiety, and vulnerable to lower level of education livelihood exertion [1]. There are many political and cultural restrictions on female sex workers (FSWs). Official denial about their existence, social marginalization, and stigmatization are accepted aspects of their lives; as a result, they resort to alcohol and drugs, which seem to help them to go through their support system in this profession. Alcohol may also be used by FSWs to cope with the stress and violence associated with commercial sex work [2].
Alcohol consumption is an accepted phenomenon in the sex trade. A greater proportion of FSWs and their clients use alcohol prior to or during sex [3]. The clients are first lured to have food and alcohol in the restaurant and following commercial sex activity ensues, it also plays a crucial role in increasing sexual risk among the commercial sex workers (CSWs) [4]. Simultaneously in this course of action they fail to realize that alcohol abuse increases and affects to their physical health, promotes illicit drug sue, poor condom negotiation, and even their victimization to sexual acts like oral sex and anal sex.

India is estimated to have 2.1 million people living with HIV, most of who have acquired the virus through heterosexual transmission 
[5]. Likewise Dimapur the largest city in the State of Nagaland; situated in one of the eastern most part of India is a commercial hub for the state having a high prevalence of HIV in the region. The intersection between alcohol use and female commercial sex work has been identified as an important predictor to high HIV prevalence among female sex workers (FSW) in several northeastern states of India. Alcohol consumption may contribute to sexual risk taking and ultimately the spread of HIV [6-8]. Studies from other countries document associations between alcohol use and high-risk heterosexual behaviours among those with and without HIV infection [9]. In India HIV transmission is primarily heterosexual and there is a concentrated HIV epidemic among female sex workers (FSWs) [10]. In several studies, it was made evident that many FSWs consume alcohol regularly before sexual encounters. In India, only a minority of the population drinks any alcohol (i.e., $2 \%$ of women and $32 \%$ of men), although it is becoming more common $[9,10]$. A national survey, however, suggests that FSWs and their male clients are more likely than other groups in India to drink. Furthermore, men who drink alcohol when visiting Indian FSWs engage in riskier sexual behaviour (e.g., unprotected anal sex) and are more likely to have HIV and other sexually transmitted infections (STIs) [11]. This quantitative study is part of a larger quantitative study designed to assess alcohol consumption patterns among female sex workers and their association with sexual risk taking [12]. The study aims to determine the factor associated with alcohol use among female sex worker in high HIV prevalence district of Dimapur in the state of Nagaland one of the north-eastsern state of India.

\section{Methods and Materials}

Data from Integrated Behavioural and Biological Assessment (IBBA) round 2 has been used; the study is a cross-sectional among FSWs which was conducted in the Dimapur district of Nagaland in 2009-2010 as a part of the large multi-center study. A detailed summary of the objectives of this data, sampling methods used, and questionnaire are described else $[13,14]$. Female sex worker is defined as female ages 18 years or older, who had sex with men in exchange for cash or kind of at least once within the past one month. The dependent variable was consumption of alcohol in the past month. For the consumption of alcohol, we used the question asked in the interview such as "During the past month have you consumed drinks containing alcohol?" The independent variable used in this study were socio-demographic characteristics, sexual risk behavior, the volume of clients per week, drug use, injecting drug use, sharing of injecting drugs with a sexual partner, currently suffering from any STI such as Chlamydia, gonorrhoea, and syphilis infection and knowledge about HIV. The socio-demographic variables include age, educational, and marital status. Variables related to sex work and sexual practices include age at first sex, age at started first sex work, venues for Soliciting and having sex with clients, volume of clients per week, and consistent condom use in every type of sexual act (veginal and anal etc.) with occasional clients, regular clients and main regular clients. Regular clients are those who recognize FSWs well and also come repeatedly, and FSWs know them and main regular clients are those who are noncommercial, non-paying male partner (husband, boyfriend, and live-in partners. Consistent condom use is defined as the every time condom use during a sexual act.

\section{Statistical analysis}

To identify factor associated with alcohol use among female sex workers, Chi-square statistics were used to see whether there is any association between the dependent and independent variable. Further binary logistic regressions were used to identify the factors which contribute in fueling the alcohol consumption and HIV seropositivity among female sex worker. Logistic regression has also used to see; whether alcohol use is a factor that influences the HIV among female sex worker or not. Three models have been used to identify the factor associated with alcohol consumption and HIV seropositivity among female sex worker in Dimapur. The first model included socio-demographic and drug use behaviour, the second model included the variables of model first and sexual behaviour of FSWs (i.e., age at first sex; as at first started sex work; place of sex work; clients volume per week) and third model of binary logistic regression included the variables of model first and model second and safe sexual practice with different type of partners and ever heard of HIV/AIDS.

\section{Results}

\section{Characteristics of females sex workers participants disaggregated by alcohol using status}

Out of the 417 female sex workers, 76.7\% (320) reported having ever used alcohol (Table 1) which displays the characteristics of female sex worker disaggregated by alcohol using status. Alcohol using female sex workers were older compared to that of nonalcohol using FSWs but the groups did not differ significantly in regards to their age at first started sex work, place of sex work and often condom use by main regular clients of female sex workers. Results shows that unmarried female sex workers had higher proportion of alcohol users $(20.0 \%)$ then that of married female sex worker (10.3\%).

Alcohol using female sex worker are more prone to use the drug for non-medical reason compared to non-alcohol using female sex workers ( $17.2 \%$ vs. $4.1 \%)$, and they reported a more sexual relationship with IDU's clients who shared needles as compared to non-alcohol using female sex worker (27.2\% vs. $9.3 \%)$. The average age at first sexual debut was 20 years, most of the alcohol using female sex worker's sexual debut was $15-20$ years $(52.2 \%)$ which was significantly higher to that of female sex worker who never used alcohol (30.9\%). A high proportion of alcohol using female sex worker started sex work at age $15-20$ years (35.9\%) higher to that of never used alcohol female sex worker (33.0\%). Never used alcohol female sex worker were more likely to served their clients at lodge/hotel $(61.9 \%)$ as against those alchol using female sex worker (59.7\%) and they were also more likely to report using condoms for most of the times of sexual act $(30.7 \%)$ as the other group of alcohol using female sex worker showed significantly lower prevelance of comdom use (13.7\%), with regular cliants ( $31.8 \%$ vs. $19.5 \%$ ) with main regular clients (husband/ boyfriends). 
Table 1 Association of alcohol use among female sex worker in last month with background characteristics. N.B: '\#'Hotel/brothel=bar; night club, brothel, dhaba, hotel and lodge; Public place=public place, vehicle, others; Home=home (client/FSWs) and rented room.

\begin{tabular}{|c|c|c|c|}
\hline Background characteristics & Ever used alcohol N=320 n (\%) & Never used alcohol N=97 n (\%) & $p$ value \\
\hline \multicolumn{4}{|l|}{ Current age } \\
\hline 18-19 Years & $38(11.9)$ & $10(10.3)$ & 0.14 \\
\hline 20-25 Years & $116(36.3)$ & $46(47.4)$ & \\
\hline$>25$ Years & 166(51.9) & $41(42.3)$ & \\
\hline \multicolumn{4}{|l|}{ Marital status } \\
\hline Unmarried & $64(20.0)$ & $10(10.3)$ & 0.001 \\
\hline Married & $116(36.3)$ & $39(40.2)$ & \\
\hline Divorced/separated & $52(16.3)$ & $23(23.7)$ & \\
\hline Widowed & $47(14.7)$ & $16(16.5)$ & \\
\hline Others & $41(12.8)$ & $9(9.3)$ & \\
\hline \multicolumn{4}{|l|}{ Educational status } \\
\hline Illiterate & $170(53.1)$ & $77(79.4)$ & 0.000 \\
\hline Up to 10 th standard & $131(40.9)$ & $17(17.5)$ & \\
\hline$>10$ th standard & 19(5.9) & $3(3.1)$ & \\
\hline \multicolumn{4}{|l|}{ Drug use } \\
\hline No & $265(82.8)$ & 93(95.9) & 0.001 \\
\hline Yes & $55(17.2)$ & $4(4.1)$ & \\
\hline \multicolumn{4}{|l|}{ Sharing of injecting drug } \\
\hline No & $233(72.8)$ & $88(90.7)$ & 0.000 \\
\hline Yes & $87(27.2)$ & $9(9.3)$ & \\
\hline \multicolumn{4}{|l|}{ Age at first sex ( Year) } \\
\hline$<15$ Year & $119(37.2)$ & $54(55.7)$ & 0.002 \\
\hline 15-20 Year & $167(52.2)$ & $30(30.9)$ & \\
\hline 21-25 Year & 18(5.6) & $5(5.2)$ & \\
\hline$>25$ Year & $16(5)$ & $8(8.2)$ & \\
\hline \multicolumn{4}{|c|}{ Age at first stared sex work ( Year) } \\
\hline$<15$ Year & $14(4.4)$ & $9(9.3)$ & 0.195 \\
\hline 15-20 Year & $115(35.9)$ & $32(33)$ & \\
\hline 21-25 Year & $70(21.9)$ & $16(16.5)$ & \\
\hline$>25$ Year & $121(37.8)$ & $40(41.2)$ & \\
\hline \multicolumn{4}{|l|}{ Place of sex work } \\
\hline Home & $92(28.8)$ & $27(27.8)$ & 0.946 \\
\hline Public place & $12(3.8)$ & $4(4.1)$ & \\
\hline Hotel/brothel based & 191(59.7) & $60(61.9)$ & \\
\hline Others & $25(7.8)$ & $6(6.2)$ & \\
\hline \multicolumn{4}{|l|}{ Clients volume per week } \\
\hline $0-4$ & $176(55)$ & $35(36.1)$ & 0.003 \\
\hline $5-9$ & $94(29.4)$ & $45(46.4)$ & \\
\hline$>=10$ & $50(15.6)$ & $17(17.5)$ & \\
\hline \multicolumn{4}{|l|}{ Condom use with } \\
\hline Occasional clients & 218 & 73 & \\
\hline Every time & $79(36.2)$ & $36(49.3)$ & 0.013 \\
\hline Most of the times & $67(30.7)$ & $10(13.7)$ & \\
\hline Sometimes/never & $72(33.0)$ & $27(37.0)$ & \\
\hline Regular clients & 305 & 82 & \\
\hline Every time & 79(25.9) & $31(37.8)$ & 0.037 \\
\hline Most of the times & $97(31.8)$ & $16(19.5)$ & \\
\hline Sometimes/never & $129(42.3))$ & $35(42.7)$ & \\
\hline Main regular clients & 238 & 55 & \\
\hline Every time & $22(9.2)$ & $6(10.9)$ & 0.473 \\
\hline Most of the times & $52(21.8)$ & $8(14.5)$ & \\
\hline Sometimes/never & $164(80.0)$ & $41(74.5)$ & \\
\hline Ever heard of HIV & & & \\
\hline
\end{tabular}




\begin{tabular}{|c|c|c|c|}
\hline No & $29(9.1)$ & $27(27.8)$ & 0.000 \\
\hline Yes & $291(90.9)$ & $70(72.2)$ & 89 \\
\hline CT & 283 & $71(79.8)$ & 0.928 \\
\hline Negative & $227(80.2)$ & $18(20.2)$ & \\
\hline Positive & $56(19.8)$ & 89 & 0.930 \\
\hline NG & 282 & $82(92.1)$ & $7(7.9)$ \\
\hline Negative & $259(91.8)$ & & 0.287 \\
\hline Positive & $23(8.2)$ & $85(87.6)$ & $12(12.4)$ \\
\hline Active syphilis & & & \\
\hline No & $266(83.1)$ & $5(16.9)$ & \\
\hline
\end{tabular}

Compared to non-alcohol using female sex worker, alcoholusing FSWs were not significantly associated to test positive for Chlamydia, gonorrhoea, and syphilis infection. Although STIs among alcohol using FSW's were not showing significant associatation but; gonorrhoea $(8.2 \%$ vs. 7.9$)$ and syphilis ( $16.9 \%$ vs. $12.4 \%$ ) were more likely to test positive compared to non-alcohol-using FSWs except Chlamydia infection. A higher proportion of alcohol using female sex worker has heard about HIV compared to non-alcohol using female sex workers $(90.9 \%$ vs. $72.2 \%)$.

\section{Determinants of alcohol use among female sex workers}

The result of binary logistic regression analysis of alcohol use among female sex worker is shown in Tables $\mathbf{2}$ and 3, which regress ever consumption of alcohol in the past month among FSW's according to selected background characteristics, sexual behaviour and contextual factors regarding alcohol use in Dimapur districts of Nagaland. In this additional analysis, those factors are not coming significant has not been included in the binary logistic regression analysis. Three models have been used to identify the factor associated with alcohol use among female sex worker.

Binary logistic regression of Alcohol use among Female sex workers found that greater than 25 years of FSWs (2.2 times, $\mathrm{P} \leq$ $0.10)$, Divorced/Separated $(0.41$ times, $p \leq 0.10),>10^{\text {th }}$ standard of education ( 0.311 times, $p \leq 0.001$ ), drug use ( 5 times, $p \leq 0.001$ ), sharing of injecting drugs with the partner (3.7 times, $p \leq 0.001$ ) were independently associated with Alcohol use respectively. Those FSWs have first sex and first started sex work at age 15-20 years were 6.3 -times $(p \leq 0.05)$ and $2.4(p \leq 0.05)$ times more likely to use alcohol respectively. Female sex workers were $66 \%$ less likely to use alcohol consumption that has 5-9 clients per week. One interesting finding of this study was that those FSWs ever heard of HIV, 36 times ( $p \leq 0.001$ ) more likely to use alcohol.

\section{Determinants of HIV seropositivity among alcohol using female sex workers}

The prevalence of HIV among alcohol using female sex worker in Dimapur districts of Nagaland was 11.3 percent. Alcohol using older (25+ years) female sex workers was more likely to have HIV seropositivity almost 9 times more likely in model 1 and model 2 of binary logistic regression. It was also reported that married FSWs those using alcohol, were less likely to have HIV. Further Alcohol using female sex worker age at first sex was 15-20 years; they were 5 times more likely to have HIV Seropositivity. Although drug use behaviour among alcohol using female sex worker was not shows significant association with HIV prevalence but; they are 4 times more likely have to HIV seropositivity. Alcohol using female sex worker were 30 times more likely to have HIV seropositivity those who served their client at lodge/hotel, and they were less likely to use a condom with all type of sexual partner. Most of the time consistent condom use with main regular clients among alcohol using female sex worker were very much less likely to have HIV seropositivity than the other counterparts.

\section{Discussion}

According to the study, about three-fourth of female sex workers in Dimapur district of Nagaland reported ever consumption of alcohol. Alcohol using female sex workers substantially differed from that of those non-using alcohol peers, they too differed substantially in regards to their demographic and sexual risk profile, and furthermore burden of sexually transmitted diseases was seen to be significantly greater in alcohol using female sex worker.

The female sex worker whose sexual debuts are early is more likely to be exposed to alcohol, which has been established links between alcohol use and early sexual experiences [15]. Regarding marital status, it was found that unmarried FSWs were more likely to consumed alcohol compared to those who had ever married. In this study alcohol using female sex worker and non-using female sex worker did not differ from one another regarding their educational status. Our results are conflicting to previous reports from this region that indicated a close connection between illiteracy and substance use for women [16-19].

The present study found that drug use for non-medical reason among alcohol using female sex workers was more common compared to non-alcohol using female sex workers. In many studies, it was found that co-use of alcohol and illicit drugs was very common in northeast India among female injecting drug users [20]. In the Present study, it was evident that younger FSW's whose age at first sex was 15-20 years were more likely to use alcohol and had higher incidence of HIV seropositivity. These findings indicate that Abusing alcohol or other drugs can impair judgment, leading a person to engage in risky sexual behaviours [21]. Chen et al. also found that younger age of involvement in the sex trade were more vulnerable to sex under the influence 
Table 2 Factors associated with Ever consumption of alcohol in the past month among FSWs in Dimapur district of northeast state of India, IBBA, round 2, 2010. ${ }^{{ }^{* 1}}$ Refers $p$-value $<0.05$ and ${ }^{1 * * 1}$ for $p$-value $<0.01$.

\begin{tabular}{|c|c|c|c|}
\hline Background Characteristics & Model 1 EXP ( $\beta$ ) & Model $2 \operatorname{EXP}(\beta)$ & Model 3 EXP ( $\beta)$ \\
\hline \multicolumn{4}{|l|}{ Current age } \\
\hline \multicolumn{4}{|l|}{$18-19$ Years $^{\circ}$} \\
\hline 20-25 Years & 1.071 & 0.813 & 1.717 \\
\hline $25+$ Years & $2.164^{*}$ & 2.348 & 1.449 \\
\hline \multicolumn{4}{|l|}{ Marital status } \\
\hline \multicolumn{4}{|l|}{ Unmarried ${ }^{\circledR}$} \\
\hline Married & 0.478 & 0.552 & 0.000 \\
\hline Divorced/separated & $0.406^{*}$ & 0.485 & 0.000 \\
\hline Widowed & 0.499 & 0.525 & 0.000 \\
\hline Others & 0.612 & 0.794 & 0.000 \\
\hline \multicolumn{4}{|l|}{ Educational status } \\
\hline \multicolumn{4}{|l|}{ Illiterate } \\
\hline Up to $10^{\text {th }}$ standard & 0.433 & 0.431 & 0.123 \\
\hline$>10^{\text {th }}$ standard & $0.311^{* * *}$ & $0.394^{* * *}$ & 1.731 \\
\hline \multicolumn{4}{|l|}{ Drug use } \\
\hline \multicolumn{4}{|l|}{$\mathrm{No}^{\circ}$} \\
\hline Yes & $4.802^{* * *}$ & $5.115^{* * *}$ & 0.123 \\
\hline \multicolumn{4}{|l|}{ Sharing of injecting drug } \\
\hline \multicolumn{4}{|l|}{$\mathrm{No}^{\circ}$} \\
\hline Yes & $3.690^{* * *}$ & $3.278^{* * *}$ & $1.731^{* *}$ \\
\hline \multicolumn{4}{|l|}{ Age at first sex (years) } \\
\hline \multicolumn{4}{|l|}{$<15$ Years $^{\circ}$} \\
\hline $15-20$ Years & & $1.724^{*}$ & $6.252^{* *}$ \\
\hline 21-25 Years & & 1.210 & 7.796 \\
\hline$>25$ Years & & 1.271 & 0.804 \\
\hline \multicolumn{4}{|l|}{ Age at first stared sex work (years) } \\
\hline \multicolumn{4}{|l|}{$<15$ Years $^{\circ}$} \\
\hline $15-20$ Years & & 2.062 & $2.416^{* *}$ \\
\hline 21-25 Years & & 2.554 & 29.891 \\
\hline$>25$ Years & & 1.234 & 1.727 \\
\hline \multicolumn{4}{|l|}{ Place of sex work } \\
\hline \multicolumn{4}{|l|}{ Home } \\
\hline Public place & & 1.409 & 0.055 \\
\hline Hotel/brothel based & & 1.121 & 0.791 \\
\hline Others & & 1.163 & 0.982 \\
\hline \multicolumn{4}{|l|}{ Clients volume per week } \\
\hline \multicolumn{4}{|l|}{$0-4^{\circ}$} \\
\hline $5-9$ & & $0.443^{* * *}$ & 0.489 \\
\hline$>=10$ & & 0.630 & 0.489 \\
\hline \multicolumn{4}{|l|}{ Condom use with } \\
\hline \multicolumn{4}{|l|}{ Occasional clients } \\
\hline \multicolumn{4}{|l|}{ Every time ${ }^{\circ}$} \\
\hline Most of the times & & & 0.413 \\
\hline Sometimes/never & & & 0.743 \\
\hline \multicolumn{4}{|l|}{ Regular clients } \\
\hline Every time ${ }^{\circ}$ & & & \\
\hline
\end{tabular}




\begin{tabular}{l|l|}
\hline Most of the times & 1.499 \\
\hline Sometimes/never & 3.531 \\
Main regular clients & \\
\hline Every time & \\
\hline Most of the times & 0.312 \\
\hline Sometimes/never & 0.475 \\
\hline Ever heard of HIV & \\
\hline No $^{\circ}$ & \\
\hline Yes & $35.629^{* * *}$
\end{tabular}

Table 3 Factors associated with HIV among alcohol using FSWs in Dimapur district of Northeast state of India, IBBA, round 2, 2010. ${ }^{{ }^{* 1} \prime}$ Refers p-value $<0.05$ and $^{1 * * 1}$ for $p$-value $<0.01$.

\begin{tabular}{|c|c|c|c|}
\hline Background Characteristics & Model 1 EXP( $\beta)$ & Model $2 \operatorname{EXP}(\beta)$ & Model $3 \operatorname{EXP}(\beta)$ \\
\hline \multicolumn{4}{|l|}{ Current age } \\
\hline \multicolumn{4}{|l|}{ 18-19 Years ${ }^{\circ}$} \\
\hline $20-25$ Years & 4.632 & 3.752 & 7.185 \\
\hline $25+$ Years & $8.996^{* *}$ & $9.414^{* *}$ & 14.674 \\
\hline \multicolumn{4}{|l|}{ Marital status } \\
\hline \multicolumn{4}{|l|}{ Unmarried ${ }^{\circ}$} \\
\hline Married & $0.353^{*}$ & $0.309^{*}$ & $0.031^{* *}$ \\
\hline Divorced/separated & 0.635 & 0.601 & $0.064^{*}$ \\
\hline Widowed & 0.619 & 0.608 & 0.188 \\
\hline Others & $0.229^{*}$ & 0.229 & 0.036 \\
\hline \multicolumn{4}{|l|}{ Educational status } \\
\hline \multicolumn{4}{|l|}{ Illiterate } \\
\hline Up to $10^{\text {th }}$ standard & 1.054 & 1.171 & 0.964 \\
\hline$>10^{\text {th }}$ standard & 1.528 & 1.845 & $15.400^{* *}$ \\
\hline \multicolumn{4}{|l|}{ Drug use } \\
\hline \multicolumn{4}{|l|}{$\mathrm{No}^{\circ}$} \\
\hline Yes & 1.491 & 1.617 & 4.151 \\
\hline \multicolumn{4}{|l|}{ Sharing of injecting drug } \\
\hline \multicolumn{4}{|l|}{$\mathrm{No}^{\circ}$} \\
\hline Yes & 0.980 & 1.076 & $0.079^{* *}$ \\
\hline \multicolumn{4}{|l|}{ Age at first sex(years) } \\
\hline \multicolumn{4}{|l|}{$<15$ Years ${ }^{\circ}$} \\
\hline $15-20$ Years & & 2.072 & $5.805^{*}$ \\
\hline 21-25 Years & & 0.390 & 0.000 \\
\hline$>25$ Years & & 3.202 & 0.000 \\
\hline \multicolumn{4}{|l|}{ Place of sex work } \\
\hline \multicolumn{4}{|l|}{ Home } \\
\hline Public place & & $8.103^{* *}$ & 0.000 \\
\hline Hotel/brothel based & & 3.054 & $30.065^{* *}$ \\
\hline Others & & 1.904 & $30.800^{*}$ \\
\hline \multicolumn{4}{|l|}{ Clients volume per week } \\
\hline \multicolumn{4}{|l|}{$0-4^{\circ}$} \\
\hline $5-9$ & & 0.937 & 0.512 \\
\hline$>=10$ & & 0.472 & 0.115 \\
\hline \multicolumn{4}{|l|}{ Condom use with } \\
\hline \multicolumn{4}{|l|}{ Occasional clients } \\
\hline \multicolumn{4}{|l|}{ Every time } \\
\hline Most of the times & & & 4.476 \\
\hline Sometimes/never & & & 0.046 \\
\hline Regular clients & & & \\
\hline Every time & & & \\
\hline
\end{tabular}




\begin{tabular}{|c|c|c|c|}
\hline Most of the times & 0.259 \\
\hline Sometimes/never & 3.205 \\
\hline Main regular clients \\
\hline Every time \\
\hline Most of the times
\end{tabular}

of alcohol [22]. Likewise a study in Kenya; it was found that HIVpositive women had their first sexual experience at a younger age than HIV-negative women, they also charged less per sexual act; adding to condom-less sexual activity, and were less likely to report a regular sexual partner, with more frequent alcohol consumption; which is approximately 11 percent among FSWs [23].

Analysis explains the relationship between alcohol use and STIs among FSWs. However there is no significant relationship between alcohol use and individual STIs among the study group but, individual STIs prevalence were higher in alcohol using FSWs. It is seen those who are serving their clients at lodge/hotel are crucial predictor to fuel the HIV seropositivity and are almost 30 times more likely to have HIV among Alcohol using FSWs. Findings also indicates that alcohols using female sex workers are extremely less likely to use a condom most of the time; irrespective of the type of sexual partner. These findings suggest that alcohol using female sex workers need to be targeted by the prevention programs with better exigency to make the HIV and STI prevention programs more successful [24-26].

\section{Conclusion}

Several factors such as drug use, marital status, educational status, age at first sex, a larger volume of clients, and sexual partners' drug injecting status were identified as having an association with drug use among FSWs. The findings of this study suggest a need to integrate intervention for alcohol use and related problems in multilevel contexts and with multiple components to effectively reducing alcohol use and to mitigate inconsistent condom use.

\section{Acknowledgements}

The authors are thankful to National AIDS Research Institute (NARI), Pune, India for providing the data of Integrated Behavioural and Biological Assessment (IBBA) to this type of study. 


\section{References}

1 Ghimire L, Smith WCS, Teijlingen ERV, Rashmi D, Nagendra PL (2011) Reasons for non-use of condoms and self-efficacy among female sex workers: a qualitative study in Nepal. BMC Womens Health 11: 42.

2 Patterns of Migration/Mobility and HIV Risk among Female Sex Workers (2008) Bangalore, Karnataka.

3 Saggurti N, Singh AK, Swain SN, Verma RK (2010) Alcohol and sexual risk behaviour among migrant female sex workers and male workers in districts with high in-migration from four high HIV prevalence states in India. AIDS Behave 4: 31-39.

4 Devine A, Bowen K, Dzuvichu B, Rungsung R, Kermode M (2010) Pathways to sex-work in Nagaland, India: implications for HIV prevention and community mobilization. AIDS Care 22: 228-237.

5 National AIDS Control Organisation (2009-2010) Annual report NACO, New Delhi.

6 Cooper ML (2006) Does drinking promote risky sexual behavior? A complex answer to a simple question. Current Directions in Psychological Science 15: 19-23.

7 Leigh BC, Stall R (1993) Substance use and risky sexual behavior for exposure to HIV issues in methodology, interpretation, and prevention. Am Psychol 48: 1035-1045.

8 Samet JH, Horton NJ, Meli S, Freedberg KA, Palepu A (2004) Alcohol consumption and antiretroviral adherence among HIV-infected persons with alcohol problems. Alcohol Clin Exp Res 28: 572-577.

9 Heravian A, Solomon R, Krishnan G, Vasudevan CK, Krishnan AK (2012) Alcohol consumption patterns and sexual risk behavior among female sex workers in two South Indian communities. Int J Drug Policy 26: 498-504.

10 Prasad R (2009) Alcohol use on the rise in India. Lancet 373: 17-18.

11 International Institute for Population Sciences (IIPS) (2005-2006) and Macro International. National Family Health Survey India, Mumbai, HIS (NFHS3).

12 Madhivanan P, Hernandez A, Gogate A, Stein E, Gregorich S, et al. (2005) Alcohol use by men is a risk factor for the acquisition of sexually transmitted infections and human immunodeficiency virus from female sex workers in Mumbai, India. Sex Transm Dis 32: 685-690.

13 Chandrasekaran P, Dallabetta G, Loo V, Mills S, Saidel T, et al. (2008) Evaluation design for large-scale HIV prevention programmes: the case of Avahan, the India AIDS initiative 22: 1-15.

14 Saidel T, Adhikary R, Mainkar M, Dale J, Loo V, et al. (2008) Baseline integrated behavioural and biological assessment among most at- risk populations in six high-prevalence states of India: design and implementation challenges. Acquir Immune Defic Syndr 2: 17-34.

15 Bowen KJ, Dzuvichu B, Rungsung R, Devine A, Hocking J, et al. (2011) Life circumstances of women entering sex work in Nagaland, northeast India. Asia Pac J Public Health 23: 843-851.

16 Medhi GK, Hazarika NC, Mahanta J (2006) Tobacco and alcohol use among the youth of the agricultural tea industry in Assam, India. Southeast Asian J Trop Med Public Health 37: 581-586.

17 Medhi GK, Hazarika NC, Mahanta J (2006) Correlates of alcohol consumption and tobacco use among tea industry workers of Assam. Subst Use Misuse 41: 691-706.

18 Chaturvedi HK, Phukan RK, Mahanta J (2003) Association of sociodemographic factors and differences in pattern of substance use: a study in selected areas of North-east India. Subst Use Misuse 38: 1305-1322.

19 Chaturvedi HK, Mahanta J (2004) Sociocultural diversity and substance use pattern in Arunachal Pradesh, India. Drug Alcohol Depend 74: 97-104.

20 Medhi GK, Mahnta J, Kermode M, Paranjape RS, Adhikary R, et al. (2012) Factor Associated with history of drug use among female sex workers (FSW) in a high HIV prevalence state of India. BMC Public health 12: 273.

21 Pando MA, Berini C, Bibini M, Fernández M, Reinaga E, et al. (2006) Prevalence of HIV and other sexually transmitted infections among female commercial sex workers in Argentina. Am J Trop Med Hyg 74: 233-238.

22 Alcohol and HIV/AIDS: Intertwining Stories. Alcohol Alerts Number 80.

23 Yiyun Chen, Xiaoming Li, Chen Zhang, Yan Hong, Yuejiao Zhou, et al. (2013) Alcohol use and Sexual Risks: use of the Alcohol Use Disorders identification Test (AUDIT) among Female Sex Workers in China. Health Care Women Int 34: 122-138.

24 Fonck K, Kaul R, Keli F, Bwayo JJ, Ngugi EN, et al. (2001) Sexually transmitted infections and aginal douching in a population of female sex workers in Nairobi, Kenya. Sex Transm Inf. 77: 271-275.

25 Samet JH, Pace CA, Cheng DM, Coleman S, Bridden C, et al. (2010) Alcohol use and sex risk behaviors among HIV-infected female sex workers (FSWs) and HIV-infected male clients of FSWs in India. AIDS and Behavior 14: 74-83.

26 Heravian A, Solomon R, Krishnan G, Vasudevan CK, Krishnan AK (2012) Alcohol consumption patterns and sexual risk behavior among female sex workers in two South Indian communities. Int J Drug Policy 23: 498-504. 